\title{
Communicative Listening Training in English- Features, Strategies and Methods
}

\author{
Tsinghong Ma \\ School of Foreign Languages, Shandong Economic University, Jinan, China, 250014 \\ Email: helenmqh@163.com
}

\begin{abstract}
The main aim of learning a foreign language is to communicate with native speakers in different situations. To achieve this goal, taking communicative approach into listening training is necessary. There are particular features in applying communicative listening training and various strategies, activities can be selected in the classroom.
\end{abstract}

Index Terms - communicative language teaching, listening training, strategies, methods

Communicative approach has been largely accepted by teachers in teaching foreign languages in classrooms. In order to apply it successfully in listening comprehension training, it's of importance for the teachers to discuss the features, strategies and methods of communicative listening training.

\section{FEATURES OF COMMUNICATIVE LISTENING TRAINING}

The focus of the features of communicative listening training is real-life Listening. It contains the following elements:

\section{A. Situations}

It would be useful if there were available a full-scale taxonomy of all the different kinds of listening situations there are, together with a statistical analysis of their relative frequencies. However, we do not know of any such study-nor are we sure that its execution is at all a practical proposition, since the immense variety of societies, individuals, situations and types of oral discourse must defy classification. On a less ambitious scale, however, it is possible to list some examples of the types of listening we might expect reasonably educated people living in a developed country to be exposed to (Ur 1984), and hope that an examination of the results might yield some useful conclusions.

Such a list is set out below, in random order. Not all of the examples are pure listening activities, but all involve some aural comprehension as an essential component of the communicative situation:

-- listening to the news/ weather fore cast/ sports report/ announcements etc. on the radio

-- discussing work/ current problems with family or colleagues

-- making arrangements/ exchanging news etc. with acquaintances

-- making arrangements/ exchanging news etc. over the telephone

-- chatting at a party/ other social gathering

-- hearing announcements over the loudspeaker ( at a railway station, for example, or airport)

-- receiving instructions on how to do something/ get somewhere

-- attending a lesson/ seminar

-- being interviewed/ interviewing

-- watching a film/ theatre show/ television program

-- hearing a speech/ lecture

-- listening to recorded/ broadcast songs

-- attending a formal occasion (wedding/ prize-giving/other ceremony)

-- getting professional advice (from a doctor, for example)

-- being tested orally in a subject of study

This list is naturally rough and incomplete; nevertheless it is fairly representative. There are certainly some useful generalizations which can be drawn from it and which have some immediate implications for classroom practice.

\section{B. Response and Other Characteristics}

For real-life listening in many (or perhaps most) cases the listener is required to give some kind of overt, immediate response to what has been said. This may be verbal (the answer to a question, for instance) or non-verbal (action in accordance with instructions or a nod of the head, for example). Even a lecturer or orator gets some sort of feedback from his audience in the form of facial expression, eye-contact, interruptions, note-taking. Only if the message is coming via electronic equipment when the speaker is neither physically present nor addressing himself to the listener as an individual, is no overt response usually required or forthcoming.

Yet many classroom listening comprehension exercises demand no response until the end of fairly long stretches of 
speech, so that when it comes this response is very largely a test of memory rather than of comprehension. Occasional exercises like these, and others that demand no overt response at all certainly have their place-I do not mean to suggest that they should not be used at all—but on the whole listening tasks should, according to Ur (1984), be based on short, active responses occurring during, or between parts of, the listening passage rather than at the end.

The nature of the learner's response is important for three main reasons. First, it is the need to produce an overt response that provides learners with their immediate motivation for listening. Second, it orients them towards certain kinds of meaning and thus helps them to structure their listening activity. Third, some kinds of response provide learners with a framework for conceptualizing the central meanings of the text and for relating them to each other.

However, this immediate response will not necessarily be the ultimate purpose of the listening. It may also serve as a preliminary to some other activity. For example, the information which learners obtain may serve as a basis for discussion, oral reports or writing. Indeed, it is when the results of successful listening contribute to some further purpose that the learners are most strongly and realistically motivated.

Ur also summarizes that most of our real-life listening activity is characterized by the following features:

1. We listen for a purpose and with certain expectations.

2.We make an immediate response to what we hear.

3.We see the person we are listening to.

4.There are some visual or environmental clues as to the meaning of what is heard.

5.Stretches of heard discourse come in short chunks.

6.Most heard discourse is spontaneous and therefore differs from formal spoken prose in the amount of redundancy, " noise" and colloquialisms, and in its auditory character.

Sometimes particular situations may lack one or more of these characteristics - when watching television we are not normally expected to respond, when listening to a lecture we may have to hear uninterrupted speech for a very long time indeed - but it is only very rarely that none of them is present at all. Classroom practice should usually incorporate such characteristics of real-life listening as those described above.

\section{Listening to Spoken English}

In Teaching the Spoken Language, Brown and Yule (1983) distinguish spoken and written language. They point out that for most of its history, language teaching has been concerned with the study of the written language. An obvious advantage of the written language is that it has been described by generations of grammar-writers and dictionary-makers There is a comforting sense in which it is possible to say that a written sentence is correct or not. The rules of writing English sentences are really rather well known and well described. Furthermore, written language does not vary greatly over a couple of centuries, and it does not vary very much depending on where it is written.

While in daily life, people speak and listen to spoken language. Spoken language, on the other hand, consists of short, often fragmentary utterances, in a range of pronunciations. There is often a great deal of repetition and overlap between one speaker and another, and speakers frequently use non-specific references (they tend to say "thing", "it" and "this" rather than "the left-handed monkey wrench", or "the highly perfumed French poodle on the sofa"). Brown and Yule point out that the loosely organized syntax, the use of non-specific words and phrases and the use of fillers such as "well", "oh" and "uhuh" make spoken language feel less conceptually dense than other types of language such as expository prose.

They point out that the implications of what we have said about typical spoken language for listening comprehension are, in a sense, less encouraging. On the one hand spoken language tends towards less specific vocabulary and far more general use of items like "thing" and "do". This initially sounds hopeful from the point of view of the foreign learner. On the other hand, it seems at least plausible that this less specific language is actually quite hard to understand unless the listener has access to information about context and background knowledge of a sort which conventional listening comprehension teaching tends not to supply. Listening comprehension consists of far more than understanding what words and sentences mean; it involves understanding what speakers mean. Until we can get some sort of handle on teaching what speakers mean by using language in particular types of context our progress in the field of teaching listening comprehension will necessarily be slow.

Brown and Yule also draw a useful distinction between two basic language functions. These are the transactional function, which is primarily concerned with the transfer of information, and the interactional function, in which the primary purpose of speech is the maintenance of social relationships.

\section{Listening with a Purpose}

Over the last two decades, as we have developed a much better understanding of the nature of the listening process, and of the processes of comprehension in general, a quite different approach to helping students with listening comprehension has been emerging. The memory problems which long pieces of discourse give rise to have been recognized; few training extracts now last longer than three minutes and many last no more than one minute. More significantly though, it has been recognized that in normal life we do not process discourse as though all of it were equally interesting or equally worthy of being remembered. In normal life we have reasons for listening, and interests and purposes which our listening serves. We are quite capable, in listening as in reading, of skimming over some bits of message which are not germane to our current purposes and then of paying particular detailed attention to those parts 
which seem to us most relevant. Increasingly, listening comprehension materials are being developed which reflect this - they do not require the student to process all of the discourse as though it were equally important but rather to listen for, and to select for attention, certain specific points in the discourse.

A natural development in methodology has been that, in order to meet the requirement that students should listen selectively to discourse, the discourse is presented to them in the context of a pre-specified task which puts them very much in the position of native speakers - where the point of listening is to put the information they have heard to use. In such circumstances it does not matter whether or not they have understood all the details of what was said. All that matters is that, in the context of the task, they have been able to construct enough of a reasonable interpretation to make a decent effort at completing the task successfully. They may actually have failed to pay attention to all of the discourse, they may have been unable to understand some parts of it, they may have had to infer - to work out — what the speaker must have meant. All this is practice in learning to listen as a native speaker listens. These are exactly the sorts of skills that we all use everyday in our own native language. With a reasonable view of success established, many more students now have the experience of success in listening to the foreign language. Indeed, it is when the results of successful listening contribute to some further purpose that the learners are most strongly and realistically motivated.

\section{LISTENING STRATEGIES}

\section{A. About Learning Strategies}

Strategies are the mental and communicative procedures learners use in order to learn and use language. Underlying every learning task is at least one strategy. However, in most classrooms, learners are unaware of the strategies underlying the learning tasks in which they are engaged. (Nunan, 1999)

Knowledge of strategies is important, because the greater awareness you have of what you are doing, if you are conscious of the processes underlying the learning that you are involved in, then learning will be more effective. Researches (Nunan 1997, Cohen 1996 etc.) show that the incorporation of a learning strategy dimension into the curriculum could help to maintain or enhance motivation, and might also lead to greater appreciation on the part of learners of the processes underlying their own learning.(Previous research has shown that the effective learner is one who is aware of learning strategies). It was also hoped that strategy training would help learners develop greater independence and control over their learning, and this, in turn, would encourage them to continue learning English on their own once their classes had stopped.

Rebecca Oxford, one of the leading teachers and researchers in the language4 learning strategies field, argues that strategies are important for two reasons. In the first place, strategies "are tools for active, self-directed involvement, which is essential for developing communicative competence" (1990) Secondly, learners who have developed appropriate learning strategies have greater self-confidence and learn more effectively. In her introduction to the field, she identifies twelve key features of strategies. According to Oxford, language learning strategies

$\diamond$ contribute to the main goal, communicative competence

$\diamond$ allow learners to become more self-directed

$\diamond$ expand the role of teachers

$\diamond$ are problem-oriented

$\diamond$ are specific actions taken by the learner

$\diamond$ involve many actions taken by the learner, not just the cognitive

$\diamond$ support learning both directly and indirectly

$\diamond$ are not always observable

$\diamond$ can be taught

$\diamond$ are flexible

$\diamond$ are influenced by a variety of factors

Oxford draws a distinction between direct strategies and indirect strategies. Direct strategies include such things as memorizing, analyzing and reasoning, and guessing intelligently. As the name suggests, these are specific procedures that learners can use to internalize the language. Indirect strategies, on the other hand, include things such as evaluating one's learning and cooperating with others.

When learning strategies are induced in the classroom, it is important to keep in mind that, as far as possible, strategies should be integrated into the ongoing process of the language lesson and underlie tasks.

\section{B. Listening Strategies}

Listening strategies are expected to develop learners' awareness of the processes underlying their own learning so that, eventually, they will be able to take greater and greater responsibility for that learning. This can be done through the adoption of a learner-centered strategy at the level of classroom action, and partly through equipping students with a wide range of effective learning strategies. Through these, students will not only become better listeners, they will also become more effective language learners because they will be given opportunities to focus on, and reflect upon the processes underlying their own learning. This is important, because if learners are aware of what they are doing, if they are conscious of the processes underlying the learning they are involved in, then learning will be more effective. Key strategies that can be taught in the listening classroom include selective listening, listening for different purposes, 
predicting, progressive structuring, inferencing, and personalizing. These strategies should not be separated from the content teaching but woven into the ongoing fabric of the lesson so that learners can see the applications of the strategies to the development of effective learning.

In addition to teaching direct strategies, such as selective listening and listening for gist, the teacher can also emphasize learning processes by stating goals at the beginning of each lesson. Such statements are important because learners are made aware of what the teacher is trying to achieve. The goal statement can be reinforced by self-check exercises at regular intervals during these courses. These will serve to remind learners of what they have learned, and give them an opportunity to monitor and evaluate their progress.

Items concerning the listening comprehension strategies were identified in the previous studies of listening. According to Bacon's Coding of Listening-comprehension Strategies (Bacon, 1992) and Vandergrif's Listening Comprehension Strategies Framework (Vandergrift, 1997), we can briefly list the strategies as follows:

\section{Metacognitive Strategies}

1) Directed Attention: e.g. concentrate; get used to speech rate; refocus.

2) Planning: e.g. decide how many times to listen to a particular tape segment; determine how to break up the segment into manageable portions; preview the new words; brainstorm the topic knowledge.

3) Defining Goals: e.g. decide what exactly to listen for; determine how much needs to be understood; decide to achieve more than last time.

4) Selective Attention: e.g. focus on the beginning and the end parts of the segments, transitional signals, repeated words or phrases, stressed words of phrases.

5) Monitoring: e.g. identify sources of difficulty; isolate problematic portions; adjust the strategies and the comprehension while necessary.

6) Evaluating: e.g. assess knowledge of topic; evaluate the comprehension and the effectiveness of strategies used; assess whether achieving the goals set beforehand or not.

\section{Cognitive Strategies}

1). Predicting: e.g. predict context based on visual clues, background knowledge, titles, questions listed in the exercises and beginning sentences of the tape segments.

2). Inferencing: e.g. infer the unknown parts by relating to personal experience, the world knowledge, or by the context; understand by verifying predications.

Top-down Processing: e.g. listen for topic, then details; concentrate on trunks; skip unknown words.

Note-taking: e.g. jot down problematic parts for resourcing later; design special forms of notes to help memory and understanding.

3. Social-affective Strategies

1) .Questioning: e.g. ask for confirmation; ask for clarification about both what and how.

2). Cooperating: e.g. discuss with peers about the problematic points as well as strategies for comprehension.

3) .Self-reassuring: e.g. provide positive self-talk; arrange rewords.

\section{Classroom Listening Activities}

\section{A. Types of Listening}

There are many different types of listening. We can classify these according to a number of variables, including listening purpose, the role of the listener, and the type of text being listened to. (Nunan 1999) These variables can be mixed and matched to give many different configurations, each of which will require a particular strategy on the part of the listener.

\section{Monologues and dialogues}

There are numerous ways in which texts can be classified. One common division is between monologues (for example, lectures, speeches, and news broadcasts), and dialogues. Monologues can be further subdivided into those that are planned and those that are unplanned. Planned monologues include media broadcasts and speeches. Many of these are texts that are written to be read, although this is not necessarily always the case. Unplanned monologues would include anecdotes, narratives, and extemporizations. Dialogues can be classified according to purpose: whether they are basically social/interpersonal or transactional in nature. Interpersonal dialogues can be further classified according to the degree of familiarity between the individuals involved.

\section{Different purposes}

Listening purpose is another important variable. Listening to a news broadcast to get a general idea of the news of the day involves different processes and strategies than listening to the same broadcast for specific information, such as the results of an important sporting event. Listening to a sequence of instructions for operating a new piece of computer software requires different listening skills and strategies than listening to a poem or short story. In designing listening tasks, it is important to teach learners to adopt a flexible range of listening strategies. This can be done by holding the listening text constant (working, say, with a radio news broadcast reporting a series of international events), and getting learners to listen to the text several times, but following different instructions each time. They might, in the first instance, be required to listen for gist, simply identifying the countries where the events have taken place. The second time they listen they might be required to match the places with a list of events. Finally, they might be required to listen 
for detail, discriminating between specific aspects of the event, or, perhaps, comparing the radio broadcast with newspaper accounts of the same events and noting discrepancies or differences of emphasis.

\section{Reciprocal and nonreciprocal listening}

Another way of characterizing listening is in terms of whether the listener is also required to take part in the interaction. This is known as reciprocal listening. When listening to a monologue, either "live" or through the media, the listening is, by definition, nonreciprocal. The listener (often to his or her frustration) has no opportunity to answer back, clarify understanding, or check that he or she has comprehended correctly. In the real world, it is rare for the listener to be cast in the role of nonreciprocal "eavesdropper" on a conversation. However, in the listening classroom, this is the normal role. In the section on the role of the learner in the listening process, I will describe a technique that can be used in the classroom for giving learners a chance to respond as they might in a conversational exchange.

\section{B. Listening for Communicative Tasks}

In Communicative Language Teaching, Littlewood (1981) groups listening activities into the following kinds according to the kind of response that the learner must produce: performing physical tasks (e.g. selecting pictures); transferring information (e.g. into tabular form); reformulating and evaluating information.

\section{Performing physical tasks}

Through the activities described under this heading, the learner is alerted to look for specific meanings, related to a task which he must perform. This encourages him to listen selectively, extracting only information which is relevant to the task. In turn, this accustoms him to the idea that the criterion for success in listening is not whether he has understood every word, but whether he has constructed enough of the meanings in order to satisfy his own communicative purpose. In these activities, success is measured in a purely practical way: whether the nonlinguistic task is performed correctly or not.

1) Identification and selection

The learner has a set of pictures. These may be similar to the pictures used for the identification tasks. He must listen to a description or dialogue, and select the picture(s) which the spoken text refers to. Alternatively, the learner may hold just one picture, and listen to two or three short descriptions or dialogues. He has to decide which spoken text refers to the picture. A well-known variant of the identification task is "bingo". Each learner has a card which depicts about nine or twelve items (e.g. numbers, objects, people or actions). The items have been chosen from a larger set of, say, thirty items. If possible, every card should depict a different selection from this set. However, the activity can also be organized on an impromptu basis by asking each learner to make his own selection from the total set and to enter the items on his card. The teacher then calls out items from the larger set. Alternatively, the learners may hear a description or dialogue in which they are mentioned. As he hears items that are on his own card, each learner must cross them off or cover all the items on his card.

For these activities, it is clear that the actual process of identification may involve varying degrees of complexity. At its simplest, it may be a question of just listening to a sequence of direct references to objects. At the other extreme, learners may have to listen to a continuous spoken text, in order to extract clues which link it to a specific situation or person.

2) Sequencing

This is a variation of the type of activity just described. Learners must now identify successive pictures that are described or mentioned, in order to place them in their correct sequence. The activity may be motivated by presenting it in various guises. For example, the pictures may represent the events in a story which learners listen to. Alternatively, they could represent the places visited by a group of tourists- the spoken text could either be in the form of a narrative, or it could consist of excerpts from conversations between the tourists as they view the different places.

3) Locating

A further variation is that learners are required to place items not into a sequence, but into their appropriate location, e.g. on a plan of a house or town. Alternatively, they may have to follow a route on a map. As other activities, the nature of the language input can vary. For example, it may consist of direct instructions which learners have to carry out; a spoken description of a scene; a conversation between two people who are discussing where to put furniture in a room or telling others about a recent journey; and so on.

4) Drawing and constructing

Learners are asked to listen to a description or discussion, and draw the scene (or plan of a house, etc.) which is described or referred to. They may first be provided with an outline which they have to complete, or a line drawing which they have to color. A variant is that learners have to construct a model or pattern, using blocks or pieces that are provided.

5) Performing other actions

Learners may be required to perform or mime other actions, as instructed or described.

In all of the activities described above, the focus has been on a practical result. The teacher can control how much of the linguistic input has to be processed by the learners, in order to achieve this result. At one extreme, it may be necessary to process every word, e.g. in order to follow precise instructions. At the other extreme, it may be necessary to scan the spoken text in order to extract a small number of relevant meanings, e.g. to identify which objects are mentioned in the course of a dialogue. In the second case, the overall complexity of the language might be far beyond 
what learners could normally cope with, since much of it is redundant to their immediate purpose: the level of difficulty depends above all on how accessible and prominent the task-relevant meanings are.

By varying the nature of the task between these two extremes, the teacher can accustom the learners to adapting their listening strategy to suit the immediate task.

\section{Transferring information}

In the activities included under this heading, learners are still required to look for specific types of meaning. It is also still the case that these meanings may be contained in a short text that has to be processed intensively, or a longer text that has to be scanned. Now, however, the outcome of the listening is no longer a physical response to the language. Learners must now extract relevant information from the text in order to transfer it to some other form, such as a table, chart or diagram. This structures and motivates the listening activity. It also creates expectations as to what meanings will occur in the spoken text, thus helping the learner to gain access to these meanings.

For example, in one of the activities in Listen to This: 1, learners are told that they will hear three monologues introducing three people: Alice, Carol, and Jane. They are provided with the following table:

\begin{tabular}{|c|c|c|c|c|}
\hline Name & Relation & Floor 1 & Age & Problem \\
\hline Alice & & & & \\
\hline Carol & & & & \\
\hline Jane & & & & \\
\hline
\end{tabular}

As the learners listen to each monologue, they must first identify which person is speaking, then fill in as much information as possible on the table. Here are the introductions:

--I hate the stairs. Sometimes the lift isn't working and you have to use the stairs. I can't get up the stairs by myself; it's my back, you see. Jane, my friend, lives on the ground floor; that's much easier. Nearly every morning I stop there for a cup of tea before I come back up here.

--I don't mind living in a tall building. Don't mind the stairs. I quite like the exercise. Of course, it's difficult for older people but I don't mind. If you live on the ground floor; I don't think it's safe. But I like my place. I've got three floors below me and three above, I feel very safe. My Mum lives here too, on the ground floor.

--Alice comes every morning. Well, nearly every morning. She's not young any more, you see, she's seventy-eight next birthday, and it's difficult for her to walk up to the top floor. I can't go up; I can't move. It's my leg; I've got a bad leg. Carol comes to see me sometimes. She lives here too, you know, in another flat. She's my daughter.

The information that learners obtain in these activities often provides a particularly convenient basis for further language activity. For example, after listening to descriptions, learners may be asked to compose written portraits of the people described, perhaps also of people known to them. After listening to interviews, they may be asked to interview each other to obtain similar information. Some materials are based on a useful technique for exploiting information obtained through listening as a stimulus for communicative interaction, which is called "jigsaw listening". For this, the class is divided into groups. Each group hears one of three different spoken texts. All texts deal with the same topic, but contain incomplete information. After obtaining the information from their own text, learners must exchange information with members of the other two groups. Between them, the texts have given the learners all the information which they need in order to solve some problem or piece together a complete account of some event. In other words, the listening provides the input for communicative activities. At the same time, of course, the prospect of taking part in communicative interaction provides learners with a strong purpose for listening.

\section{Reformulating and evaluating information}

After gradually decreasing the specific preparation which he gives the learners as to what meanings they should expect or seek in the spoken text, the teacher may decide to give learners a more global task, oriented towards the text as a whole. For example, a natural development of the information-transfer activities discussed above is that learners should be asked to reformulate the important content in their own words, in the form of notes or a summary. Alternatively, learners may be required to evaluate the information contained in the spoken text, which may thus serve as a stimulus for written argument or group discussion. Again, these activities may be further motivated by their function in a broader context of activity, such as a role-playing exercise.

\section{Authenticity}

In many language classrooms, learners listen to material created specifically for language learning. Such material provides security and comfort, and helps learners to see the various patterns and systems that make up the language. However, it is also essential for learners to listen to authentic texts. They usually contain linguistic features more usually found in written rather than spoken language. There are few of the overlaps, hesitations, and false starts found in authentic texts, and there is very little negotiation of meaning. These differences do not always adequately prepare learners for dealing with genuine communication either inside or outside the classroom, because some of the features of authentic communication that rarely appear in non-authentic texts (such as repetition, requests for clarification, and so on) actually facilitate comprehension. Also, the use of authentic sources leads to greater interest and variety in the 
material that learners deal with in the classroom.

Authenticity is, of course, a relative issue. In a sense, as soon as you take language out of the context for which it was created it becomes "deauthenticated". Modifications also sometimes have to be made because speakers have used low frequency vocabulary or unusual grammatical structures that will distract or confuse the listener. Speakers also occasionally use language that is unacceptable for other reasons. Imagine giving a group of elementary students a piece of recording from an American TV talk show. They would probably not understand it and they would become very demoralized. And that demoralization would undermine the very reasons for giving students reading and listening material. There are three reasons: (Harmer, 2000)

\section{Being better listeners}

Clearly the most obvious reason for giving students listening material is to encourage them to be better listeners. In the broadest sense, it is clear that the more reading and listening we give them (and which they succeed with) the better they will become at listening in English.

\section{Acquiring language}

Students who read and listen a lot seem to acquire English better than those who do not. In other words, one of the main advantages of reading and listening for students is that it improves their general English level. Some of the language in the texts they read and listen to is acquired by them-provided, of course, that the input is comprehensible. Indeed we could go further: without a lot of exposure to listening material students who learn languages in classrooms are unlikely to make much progress.

\section{Success}

Students are frequently made nervous by reading and listening material. It looks incredibly difficult to them and it is incredibly difficult. When teachers present students with texts they cannot understand, the effect is extraordinarily demoralizing. But when teachers choose the right kind of material (and use appropriate teaching techniques) and the students are successful, then the benefits are obvious. In other words, if we can say to our students that they have read (or listened to) something difficult but that they have managed to understand it then they have every reason to feel triumphant. And because they have been successful the barriers to reading and listening are slightly lowered. A frequent diet of successful reading makes students more confident when they read in English: successful listening classes make students better able to cope with listening to English.

We have now seen how obviously non-authentic material would not necessarily make our students better listeners or readers, especially since they would not be acquiring real language. But we have also seen how students would become unsuccessful and demoralized if they were prevented with language that was simply too difficult for them (as authentic material can be). Both extremes are obviously not useful for our purposes.

What we need, therefore, are texts which students can understand the general meaning of, whether they are truly authentic or not. But texts - whether authentic or not - must be realistic model of written or spoken English. If teachers can find genuinely authentic material which their students can cope with that will be advantageous; if not they should be using material which simulates authentic English. In simple terms the texts should be roughly-tuned rather than finely-tuned.

\section{Visual Materials and Multi-media}

Some environmental, usually visual, accompaniment to heard discourse is a characteristic of most listening situations. In the classroom these environmental clues will usually be represented by different kinds of visuals: pictures, sketches on the blackboard or overhead projector, flannel-or magnet-board cut-outs, objects. The presence of such materials is of immense value in contextualizing and bringing to life the listening situation as well as in aiding comprehension of the language. Some kind of visual clue is essential in any language-learning activity based on face-to face communication.

Visuals have an important function as aids to learning, simply because they attract students' attention and help and encourage them to focus on the subject in hand. It is relatively difficult to concentrate on spoken material that is heard "blind", far easier if there is something relevant to look at. If this something is conspicuous, colorful, humorous, dramatic or in motion - so much the better: striking and stimulating visual aids are likely to heighten students' motivation and concentration. The teacher can be her own visual aid, of course, by acting or miming - but there is such a thing as overdoing it. It's possible that students so entertained by the antics of their teacher that they were actually distracted from what was being said.

\section{Pictures and Diagrams as Task-bases}

A distinction must be drawn between visuals-based exercises and visuals-aided ones. In the latter, the visual may appear in the form of one big poster, and provides information on which the teacher can base the listening text; whereas in visuals-based exercises, each student has his own copy of the material and uses it not only to get information but also as an answer-sheet on which he is to mark his responses to tasks, such as noting inconsistencies, filling in missing items, making changes and so on. Visuals-based exercises are interesting to do and potentially very effective, so recently published listening-comprehension books usually include a number of examples.

1) Pictures

Picture-based activities are suitable on the whole for younger learners. Pictures used should be clear representations of objects, people and scenes whose description is more or less within the lexical range of the class. They should include enough detail and variation to allow for plenty of description and imaginative elaboration. Black-and-white 
cartoon-type sketches are best as they are usually very clear and easily reproduced.

2) Diagrams

The word diagram here is used in a slightly wider sense than is usual, to denote any representation of information in diagrammatic form - not just graphs or family trees, but also maps, plans, tables and so on. Older students are usually familiar with diagrammatic conventions and can "read" such material readily. The advantages of diagrams as bases for task-centered activities derive from the fact that they (diagrams) are designed to convey a large number of facts clearly and quickly without necessitating a heavy load of reading. Hence one simple diagram can generate a large amount of language to explain, describe of comment. Moreover, diagrams can represent information on a wide variety of topics and express many different relationships, so that much more varied subject matter is made available than would be possible using only pictures.

Both pictures and diagrams should be simple enough to be grasped at a glance. Over-detailed pictures are confusing and difficult to scan. Complicated diagrams are even worse: faced with elaborate graphs or maps students will have to spend some minutes working out what it all means before they can even begin to think about listening, and will also be delayed during the listening passage itself finding their way about the material in order to make appropriate responses. Similarly, any writing on a diagram should be kept to a minimum. Simply drawn symbols with lines to show relationships between them are quickly grasped; reading words takes much longer. A few isolated written words are almost inevitable in many diagrams, but full sentences should be avoided.

\section{Multi-media}

Nowadays multi-media has been widely used in language lab. It offers us new and attracting ways to teach listening. The major advantage is that students can see people speaking and can have a visual context for what is being said. And the pictures on the screen are much clearer than those of video tapes.

With this means, we have some basic video-specific techniques:

1) Silent viewing

One of the commonest techniques with video material is silent viewing. This acts as a powerful predictive exercise. The teacher plays the video CD (or disc) with the sound turned off. The students speculate about what the characters are saying. Only then do they watch the tape with sound to check whether their predictions are right.

2) Freeze frame

The teacher might create expectations by freezing a frame on the screen. The students can predict what the characters will say.

3) Sound only

Video CD (or disc) is sometimes used very mush like audio tape. Students listen to the sound only. Their listening task may be to say where the conversation is taking place and who the speakers are, for example. Then they watch the extract to see if they were right.

4) Jigsaw viewing

We have already discussed jigsaw listening. With video CD or disc, one technique is to let half the class watch without sound and the other half hear without a picture. They can then compare notes and build a complete picture of what happened before watching the video with both picture and sound. A variation of this for half the students to sit with their backs to the screen while the other half tells them what is happening while the video is being shown. When the first half then watch the video they can see how accurately it has been described to them.

Video material can contextualize listening material in a very beneficial way. There is still a place for audio cassettes, however. They provide a focus for the spoken language without the distractions that pictures can sometimes bring.

\section{E. Skills Integration}

The division of the four main language "skills" seems to suggest that in some way the skills are separate and should be treated as such: on one day students will concentrate on reading, and reading only, on the next speaking and only speaking, etc. In fact this position is clearly ridiculous for two reasons. Firstly it is very often true that one skill cannot be performed without another. It is impossible to speak in a conversation if you do not listen as well, and people seldom write without reading - even if they only read what they have just written. Secondly, though, people use different skills when dealing with the same subject for all sorts of reasons.

Conversation is not usually thought of as a listening exercise; and yet it is the culmination of all kinds of aural practice in that it is easily the most common context of listening activity in real life. When a foreign-language learner can keep up his end in ordinary speech transactions with native speakers, he can claim to be proficient in the oral skills. Usually "listening comprehension" has been treated as if it were an isolated skill-and in the classroom it can be practiced as such up to a certain point; but in the long run it must obviously be integrated with active speech production. A normal member of society must both listen and be listened to, absorb the speech of others and produce his own; and the two activities are commonly practiced together in the classroom. Listening within a conversation is a more complex process than listening in other situations: it is not enough just understand what the other participants are saying; very often we use the time they are talking not only to listen but also to start formulating our own reply, and to watch out for an opportunity to cut in with it. Someone who listens to a lecture may take notes and then write a report of the lecture. The same person might also describe the lecture to friends or colleagues, and follow it up by reading an article that the lecturer suggested. 
In these cases, and in many more, the same experience or topic leads to the use of many different skills, and in our teaching we will try to reflect this. Students involved in communicative listening activity will have to do some speaking or writing or reading in order to accomplish the task which the activity asks them to perform. Students will be asked to write, but on the basis of reading, listening or discussing.

Often our activities will have a focus on one particular skill, it is true. So that at a certain stage the students will concentrate on listening ability. But the focus can later shift to one or more of the other skills.

\section{CONCLUSION}

With the thorough understanding of the features of communicative listening practice and the application of proper strategies and teaching methods, the teachers can effectively take communicative approach into the classrooms and the objectives of the class can be possibly achieved. It is obvious that more exploring work needs to be done concerning about the above and thus communicative listening approach could be developed.

\section{REFERENCES}

[1] Bacon, S.M. (1992). Phases of Listening to Authentic Input in Spanish: a descriptive Study. Foreign Language Annals,25-4.

[2] Brown G. \& Yule G. (1983). Teaching the Spoken Language. Cambridge: Cambridge University Press.

[3] Cohen, A.D., (1996). Verbal reports as a source of insight into second-language learner strategies, in Applied Language Learner, 7 (1).

[4] Harmer, J. (2000). How to Teach English. Beijing: Foreign Language Teaching and Research Press.

[5] Littlewood, W. (1981). Communicative Language Teaching: An Introduction. Cambridge: Cambridge University Press.

[6] Nuan, D. (1989). Designing Tasks for the Communicative Classroom. Cambridge: Cambridge University Press.

[7] Nunan D. (1997).Strategy training in the language: An empirical investigation. RELC Journal, (26):56 81.

[8] Nuan, D. (1999). Second Language Teaching and Learning. Heinle \& Heinle.

[9] Oxford, R. (1990). Language Learning Strategies: What Every Teacher Should Know. Boston: Newbury House.

[10] Richard, J.C. and Rodgers, T.S. (1986). Approaches and Methods in Language Teaching: A Description and Analysis Cambridge University Press.

[11] Widdowson, H.G. (1978). Teaching Language as Communication. Oxford: Oxford University Press.

[12] Ur, P. (1984). Teaching Listening Comprehension. Cambridge: Cambridge University Press.

[13] Vandergrift, L. (1997). The Listening Strategies of Second Language (French) Listeners: a descriptive Study. Foreign Language Annals,30-3

Tsinghong Ma was born in Shandong Province, China in 1969. She received her M.A. degree in English from Shandong University, China in 2003.

She is currently an associate professor in the School of Foreign Languages, Shandong Economic University, Jinan, China. Her research interests include foreign language education; cross-culture communication and English literature. 